\title{
Sulfonamides identified as plant immune-priming compounds in high-throughput chemical screening increase disease resistance in Arabidopsis thaliana
}

\author{
Yoshiteru Noutoshi ${ }^{1}{ }^{*}$, Mika Ikeda ${ }^{1}$, Tamio Saito ${ }^{2}$, Hiroyuki Osada ${ }^{2}$ and Ken Shirasu ${ }^{3}$ \\ ${ }^{1}$ Research Core for Interdisciplinary Sciences, Okayama University, Okayama, Japan \\ ${ }^{2}$ Chemical Biology Core Facility, RIKEN Advanced Science Institute, Saitama, Japan \\ ${ }^{3}$ RIKEN Plant Science Center, Yokohama, Japan
}

\section{Edited by:}

Xin Li, University of British Columbia, Canada

\section{Reviewed by:}

Darrell Desveaux, University of Toronto, Canada

Keiko Yoshioka, University of Toronto, Canada

Robin Katrina Cameron, McMaster

University, Canada

\section{${ }^{*}$ Correspondence:}

Yoshiteru Noutoshi, Research Core for Interdisciplinary Sciences, Okayama University, 3-1-1 Tsushima-naka,

Kita-ku, Okayama 700-8530, Japan. e-mail:noutoshi@cc.okayama-u.ac.jp
Plant activators are agrochemicals that protect crops from diseases by activating the plant immune system. To isolate lead compounds for use as practical plant activators, we screened two different chemical libraries composed of various bioactive substances by using an established screening procedure that can selectively identify immune-priming compounds. We identified and characterized a group of sulfonamide compounds - sulfameter, sulfamethoxypyridazine, sulfabenzamide, and sulfachloropyridazine - among the various isolated candidate molecules. These sulfonamide compounds enhanced the avirulent Pseudomonas-induced cell death of Arabidopsis suspension cell cultures and increased disease resistance in Arabidopsis plants against both avirulent and virulent strains of the bacterium. These compounds did not prevent the growth of pathogenic bacteria in minimal liquid media at $200 \mu \mathrm{M}$. They also did not induce the expression of defense-related genes in Arabidopsis seedlings, at least not at 24 and $48 \mathrm{~h}$ after treatment, suggesting that they do not act as salicylic acid analogs. In addition, although sulfonamides are known to be folate biosynthesis inhibitors, the application of folate did not restore the potentiation effects of the sulfonamides on pathogen-induced cell death. Our data suggest that sulfonamides potentiate Arabidopsis disease resistance by their novel chemical properties.

Keywords: Arabidopsis thaliana, Pseudomonas syringae, plant activator, immune-priming, hypersensitive cell death, sulfonamide, high-throughput chemical screening

\section{INTRODUCTION}

Plants have an innate immune system that requires the phytohormone salicylic acid (SA) for disease resistance against pathogens, including fungi, bacteria, and viruses (Vlot et al., 2009). Upon pathogen infection, plants recognize pathogen-derived effector molecules by using cytosolic immune sensors and activate SA biosynthesis to mount disease resistance responses (Dangl and Jones, 2001). This often results in a hypersensitive response (HR) that leads to the rapid induction of programed cell death at sites of infection (Mur et al., 2008).

Plant activators are agrochemicals that confer disease resistance to crops by activating plant immune systems. Due to their nature, plant activators work on host plants and not on pathogens; therefore, no drug-resistant microbes have emerged as a result of their longstanding use in the fields. This durability is one of the advantages of plant activators. Probenazole (3-prop-2-enoxy1,2-benzothiazole 1,1-dioxide, Oryzemate ${ }^{\circledR}$ ) is a practically used plant activator that was incidentally discovered 35 years earlier through fungicide screening (Watanabe et al., 1977). Probenazole protects rice against blast fungus and bacterial blight without exerting antimicrobial activities. It is used prophylactically and can, as a result, decrease not only yield loss but also the usage of commonly used pesticides and farmer's workloads. Probenazole does not act like an SA analog and it might induce a primed state in plants for defense responses. Defense priming is known as a unique physiological state that can be induced by treatment with some natural or synthetic compounds and by wounding. Primed plants show a more rapid and robust activation of defense responses against subsequent challenges by microbes, insects, or abiotic stress (Conrath, 2011). The chemical effects of probenazole have been found to be exerted through accumulation of SA in Arabidopsis, tobacco, and rice (Yoshioka et al., 2001; Nakashita et al., 2002; Iwai et al., 2007; Umemura et al., 2009). However, the precise mode of action of probenazole has not yet been identified.

The success of probenazole promoted the hunt for plant activators from synthetic chemicals or biotic sources by using various approaches. A number of bioactive molecules were subsequently isolated, including BTH ( $S$-methyl 1,2,3-benzothiadiazole-7carbothioate; Schreiber and Desveaux, 2008). BTH (Actigard ${ }^{\circledR}$, formerly registered as $\mathrm{BION}^{\circledR}$ ) is the synthetic analog of SA and is actually used in the field as a treatment for certain diseases of cole crops, leafy vegetables, tomatoes, and tobacco (Gorlach et al., 1996; Lawton et al., 1996). INA (2,6-dichloroisonicotinic acid) is also a potent SA analog but it is not used practically due to its phototoxic effects (Ward et al., 1991). This is also the case with other commercially available plant activators that induce a strong defense response, which is often associated with severe growth suppression, when they are overused (Shirano et al., 2002; Zhang et al., 2003; Noutoshi et al., 2005, 2006; Yang et al., 2012). 
Tiadinil (V-get ${ }^{\circledR}$ ) and isotianil (Stout ${ }^{\circledR}$ ) are recently registered plant activators that mainly target the rice cultivation market (Himmler, 2004; Tsubata et al., 2006). Their mechanism of action is likely to be different from that of probenazole. Tiadinil has been found to be metabolized in plants to form SV-03, which induces the expression of defense genes without SA accumulation (Yasuda et al., 2006). Judging from their molecular structures, these compounds could have been developed by modifying pre-existing commercial compounds.

Like human drug discovery, large-scale screening of a broad range of compounds is useful in identifying lead compounds that could be novel plant activators applicable to various crops. However, evaluation of chemical effects on plant disease resistance by using actual plants and pathogens requires a large quantity of chemicals, thus restricting the range of chemicals that can be tested. Recently, a bulk bioproduction technique was developed for rare monosaccharides, which helped identify D-allose and Dpsicose as disease resistance inducers in rice (Kano et al., 2010, 2011). Establishment of small-scale chemical screening procedures using young Arabidopsis seedlings has enabled the screening and identification of bioactive plant activators from a chemical library that included a large number of various small organic molecules (Serrano et al., 2007; Schreiber etal., 2008; Knoth et al., 2009). However, simple inducers of defense responses such as chemical elicitors or SA analogs could be associated with phytotoxicity. To avoid such unfavorable side effects, the candidate lead compounds are expected to potentiate but not constitutively induce plant immune responses.

In a previous study, we established a high-throughput assay system that could quantitatively monitor cell death in Arabidopsis suspension-cultured cells (Noutoshi et al., 2012a). Using this method, we evaluated the effects of various chemical compounds on avirulent pathogenic Pseudomonas-induced cell death. To selectively identify compounds that enhance but not induce cell death, cell death inducers were eliminated by evaluating their chemical effects on cell viability in the absence of a pathogen, in parallel. Thus, several plant immune-priming compounds could be identified from a chemical library of 10,000 diverse small molecules (Noutoshi et al., 2012a).

In this study, we screened two chemical libraries composed of bioactive molecules and natural products and identified four sulfonamides as plant immune-priming compounds. These chemicals potentiated pathogen-induced cell death and increased disease resistance in Arabidopsis plants.

\section{MATERIALS AND METHODS CHEMICALS}

A commercially available chemical library of 1,000 medical drugs, 500 natural products with unknown biological properties, and 420 non-drug bioactive compounds was purchased from a chemical supplier (The Spectrum Collection; $10 \mathrm{mM}$ in DMSO; MicroSource Discovery Systems Inc., Gaylordsville, CT, USA). Note that the 11 compounds in this library assigned as prohibited imports by customs regulations and were not tested. A publicly available chemical library of 768 chemicals composed of bioactive molecules and natural products was obtained from the RIKEN Natural Products Depository (NPDepo800; 10 mg/mL in DMSO;
RIKEN ASI, Saitama, Japan; Osada, 2010). Sulfamethoxypyridazine (S0591) and sulfabenzamide (S0582) were purchased from Tokyo Chemical Industry (Tokyo, Japan). Sulfameter (sulfamethoxydiazine, S0383), sulfachloropyridazine (S9882), and sodium salicylate (S3007) were from Sigma-Aldrich (St. Louis, MO, USA).

\section{PLANT MATERIALS AND GROWTH CONDITIONS}

Arabidopsis suspension-cultured cells were grown in liquid media containing MS with 3\% sucrose supplemented with $0.5 \mathrm{mg} / \mathrm{L}$ MES (pH 5.7), $0.5 \mathrm{mg} / \mathrm{L}$ naphthaleneacetic acid, and $0.05 \mathrm{mg} / \mathrm{L}$ 6-benzyl amino purine under long-day conditions (Menges and Murray, 2002; Maor et al., 2007). For gene expression analysis, $A$. thaliana ecotype Columbia was grown on half-MS agar medium ( $1 \%$ sucrose) at $22^{\circ} \mathrm{C}$ under long-day conditions (16-h light/8-h dark cycles). To assay for disease resistance, plants were grown hydroponically at $22^{\circ} \mathrm{C}$ under short-day conditions (8-h light/16h dark cycles). For growth assays, Arabidopsis seeds were sterilized and stored at $4^{\circ} \mathrm{C}$ for 4 days to break dormancy. The seeds were then dispensed into 96-well plates and grown in half-MS liquid medium supplemented with $1 \%$ sucrose with $1-50 \mu \mathrm{M}$ of the chemicals. The plates were subsequently incubated at $22^{\circ} \mathrm{C}$ under long-day conditions.

\section{ASSAY FOR CHEMICAL EFFECT ON THE CELL DEATH OF Arabidopsis SUSPENSION CULTURES}

The method used has been previously described (Noutoshi et al., 2012a). Arabidopsis suspension cells were dispensed into each well of 96-well plates with deep wells, and 10-100 $\mu \mathrm{M}$ of the chemicals were applied into two wells. DMSO and SA were used as negative and positive controls, respectively. After 1-h incubation, Pseudomonas syringae pv. tomato DC3000 (Pst) avrRpm1 (final concentration; $\mathrm{OD}=0.2$ in MS medium without hormones) was applied into one of the duplicated wells. As a mock, MS medium without bacteria was used. After cocultivation on a shaker for $21 \mathrm{~h}$ under long-day conditions at $22^{\circ} \mathrm{C}$, cells were stained with $1 \%$ Evans blue dye. The cells were then washed four times with $1 \mathrm{~mL}$ of water and any incorporated dye was extracted with $400 \mu \mathrm{L}$ of an elution solution (50\% methanol, 1\% SDS). The absorbance at $595 \mathrm{~nm}$ was measured by a microplate reader. Cell viability was calculated as a relative value with the negative control considered as 100 .

\section{PLANT CHEMICAL TREATMENTS AND RNA EXPERIMENTS}

For RNA experiments with pathogen-infected samples, Arabidopsis WT seedlings (Columbia ecotype) grown on half-MS agar plates ( $1 \%$ sucrose) for 1 week under short-day conditions, that is, $8 \mathrm{~h}$ light/16 h dark, were transferred onto rockwool and hydroponically cultivated at $22^{\circ} \mathrm{C}$. After 3 weeks, plants were transferred into small pots supplemented with or without $100 \mu \mathrm{M}$ solution of each chemical for 3 days before spray-inoculation with bacteria. Rosetta leaves were collected in $2 \mathrm{~mL}$ tubes and frozen in liquid nitrogen. For experiments with the chemical-treated samples without the pathogen, Arabidopsis seedlings (Col) grown in half-MS medium ( $1 \%$ sucrose) for 2 weeks were soaked in liquid half-MS medium ( $1 \%$ sucrose) supplemented with $100 \mu \mathrm{M}$ of the chemicals. The plants were incubated for 24 or $48 \mathrm{~h}$ at $22^{\circ} \mathrm{C}$, and 
the seedlings were collected in $2 \mathrm{~mL}$ tubes and frozen in liquid nitrogen.

The samples were crushed with four zirconia balls $(\varnothing, 2 \mathrm{~mm})$ by using a Shake Master Neo (BMS, Tokyo, Japan). Total RNA was extracted using the PureLink Micro-to-Midi Total RNA Purification System with the on-column DNase treatment procedure (Invitrogen, Carlsbad, CA, USA), and RNA concentrations and purity were measured with a spectrometer at 260 and 260/280 nm, respectively (BioPhotometer Plus, Eppendorf, Germany). cDNA was synthesized with a PrimeScript RT reagent kit and with gDNA Eraser (Perfect Real Time; Takara, Shiga, Japan). Quantitative reverse transcriptase polymerase chain reaction (qRT-PCR) amplifications were performed in 96-well plates with a LightCycler ${ }^{\circledR} 480$ real-time thermocycler (Roche Diagnostics, Basel, Switzerland) using a KAPA SYBR Fast qPCR Kit (KapaBiosystems, Woburn, MA, USA). Quantification of the target transcript was carried out using the LightCycler 480 internal software Absolute Quantification 2nd Derivative Max and normalized to Actin2. The primers were $5^{\prime}$-CCGCTCTTTCTTTCCAAGC-3' and $5^{\prime}$-CCGGTACCATTGTCACACAC- $3^{\prime}$ for Actin2, 5'TGATCCTCGTGGGAATTATGT- $3^{\prime}$ and $5^{\prime}$-TGCATGATCACATCATTACTTCAT-3' for pathogenesis-related 1 (PR1), and 5'-CTTAGCCTCACCACCAATGTTG-3' and 5' -TCCCGTAGCATACTCCGATTTG-3' for At3g57260.

\section{BACTERIAL GROWTH ASSAY}

Pseudomonas syringae pv. tomato DC3000 was precultured in M9 minimal medium $\left(\mathrm{Na}_{2} \mathrm{HPO}_{4}, 7 \mathrm{mg} / \mathrm{mL} ; \mathrm{KH}_{2} \mathrm{PO}_{4}, 3 \mathrm{mg} / \mathrm{mL}\right.$; $\mathrm{NaCl}, 0.5 \mathrm{mg} / \mathrm{mL} ; \mathrm{NH}_{4} \mathrm{Cl}, 1 \mathrm{mg} / \mathrm{mL}$; thiamin, $5 \mu \mathrm{g} / \mathrm{mL} ; \mathrm{MgSO}_{4}$, $0.12 \mathrm{mg} / \mathrm{mL}$; glucose, $4 \mathrm{mg} / \mathrm{mL})$ with kanamycin $(50 \mu \mathrm{g} / \mathrm{mL})$ at $28^{\circ} \mathrm{C}$ and was inoculated into fresh $\mathrm{M} 9$ medium to a final optical density of 0.02 at $600 \mathrm{~nm}\left(\mathrm{OD}_{600}\right)$. The medium was supplemented with sulfonamide $(200 \mu \mathrm{M})$ or hygromycin $(100 \mu \mathrm{g} / \mathrm{mL})$ and the growth of bacteria was monitored by measuring the absorbance at $600 \mathrm{~nm}\left(\mathrm{OD}_{600}\right)$.

\section{ENZYME ASSAY FOR SA GLUCOSYLTRANSFERASE}

Enzyme assays for SA glucosyltransferase (SAGT) activity were performed as described previously (Noutoshi et al., 2012a). Each assay $(40 \mu \mathrm{L})$ mixture contained $2.5 \mu \mathrm{g} / \mathrm{mL}$ of UGT74F1, $0.28 \mathrm{mM}$ SA, $0.33 \mathrm{mM}$ UDP-glucose, $14 \mathrm{mM}$ 2-mercaptoethanol in $50 \mathrm{mM}$ MES, pH 8.0. Then, $100 \mu \mathrm{M}$ each of sulfonamide or imprimatin A2, one of the immune-priming compounds which we identified in the previous study (Noutoshi et al., 2012a), was added to the reaction mixes and incubated at $30^{\circ} \mathrm{C}$ for $30 \mathrm{~min}$ before the reaction was stopped by the addition of $8 \mu \mathrm{L}$ of $50 \%(\mathrm{v} / \mathrm{v})$ trichloroacetic acid. SAG was detected with HPLC by using a fluorescence detector (excitation, $295 \mathrm{~nm}$; emission, $370 \mathrm{~nm}$ ).

\section{ASSAY FOR DISEASE RESISTANCE IN PLANTS}

Inoculation and measurement of bacterial growth in plants were performed as described previously (Weigel and Glazebrook, 2002). Arabidopsis seedlings grown on MS agar plates for 1 week under short-day conditions were transferred onto rockwool and hydroponically cultivated at $22^{\circ} \mathrm{C}$. After 3 weeks, plants with rockwool were transferred into small pots and supplied with water containing various chemicals $(100 \mu \mathrm{M})$ or SA $(50 \mu \mathrm{M})$. After 3 days, freshly grown bacteria of both Pst and Pst-avrRpm1 strains were resuspended in $10 \mathrm{mM} \mathrm{MgCl}_{2}\left(\mathrm{OD}_{600}=0.002\right)$ and were used to inoculate leaves with a needle-less syringe. Then, $50 \mu \mathrm{M}$ leaf disks were then punched out with a sterile cork-borer at 0 and 3 days after inoculation. Samples were collected in a $2-\mathrm{mL}$ tube and ground with zirconia balls $(\varnothing, 2 \mathrm{~mm}$ ) with $500 \mu \mathrm{L}$ of $10 \mathrm{mM}$ $\mathrm{MgCl}_{2}$. Dilution series of each sample were spread on agar media containing kanamycin and rifampicin, and the number of bacteria inside the leaves was calculated.

\section{RESULTS \\ ISOLATION OF FOUR SULFONAMIDES AS PLANT IMMUNE-PRIMING COMPOUNDS}

By using the previously established chemical screening system (Noutoshi etal., 2012a), we tried to identify compounds that enhance but not induce the death of Arabidopsis suspensioncultured cells triggered by infection with avirulent pathogenic Pst-avrRpm1. In this study, we screened two different chemical libraries. One is a commercially available library that contains 2,000 small organic molecules and is composed of known pharmaceutical drugs, experimental bioactives, and natural products supplied by MicroSource Discovery Systems Inc. The other is a publicly available NPDepo library provided by RIKEN, which consists of 768 bioactive molecules and natural products (Osada, 2010). After three replications of the screening procedures, the candidate chemicals were reassessed for their concentrationdependent ability to promote immune responses. The various compounds that enhanced pathogen-induced cell death reproducibly were isolated. These candidate molecules were classified into several groups based on both bioactivities and molecular structures. Here, we characterized one of these groups, which consists of four different sulfonamide compounds: sulfameter (SFM), sulfamethoxypyridazine (SMP), sulfabenzamide (SBA), and sulfachloropyridazine (SCP; Figure 1). SFM and SMP were isolated from the MicroSource library, and SBA and SCP were from the NPDepo library (Figure 1).

These sulfonamide compounds were treated with Arabidopsis suspension cells at varied concentrations, as shown in Figure 2. The rates of cell death were then quantitatively measured after cocultivation with Pst-avrRpm1 for $21 \mathrm{~h}$. We found that the compounds upregulated the cell death induced by Pst-avrRpm1 in a concentration-dependent manner (Figure 2). They did not exhibit apparent toxicity with respect to cell viability in the absence of pathogen challenge. The cell death-enhancement activities of these compounds were weaker than those of SA, which functions as an endogenous potentiator for pathogen-induced cell death (Shirasu et al., 1997).

\section{EFFECT OF THE SULFONAMIDES ON DISEASE RESISTANCE IN Arabidopsis PLANTS}

To examine if these sulfonamide compounds can function in plants, they were applied to Arabidopsis seedlings and their disease resistance was analyzed. The roots of hydroponically grown Arabidopsis seedlings were drenched in water solutions supplemented with each of the sulfonamides at the concentration of $100 \mu \mathrm{M}$; the positive and negative controls were $50 \mu \mathrm{M}$ of SA and DMSO, respectively. After incubation for 3 days, each strain of 
<smiles>COc1cnc(NS(=O)(=O)c2ccc(N)cc2)nc1</smiles>

Sulfameter

(SFM)<smiles>Nc1ccc(S(=O)(=O)NC(=O)c2ccccc2)cc1</smiles>

Sulfabenzamide (SBA)<smiles>COc1ccc(NS(=O)(=O)c2ccc(N)cc2)nn1</smiles>

Sulfamethoxypyridazine (SMP)<smiles>Nc1ccc(S(=O)(=O)Nc2ccc(Cl)nn2)cc1</smiles>

Sulfachloropyridazine (SCP)

FIGURE 1 | Chemical structures of the sulfonamide compounds isolated from the chemical screening.

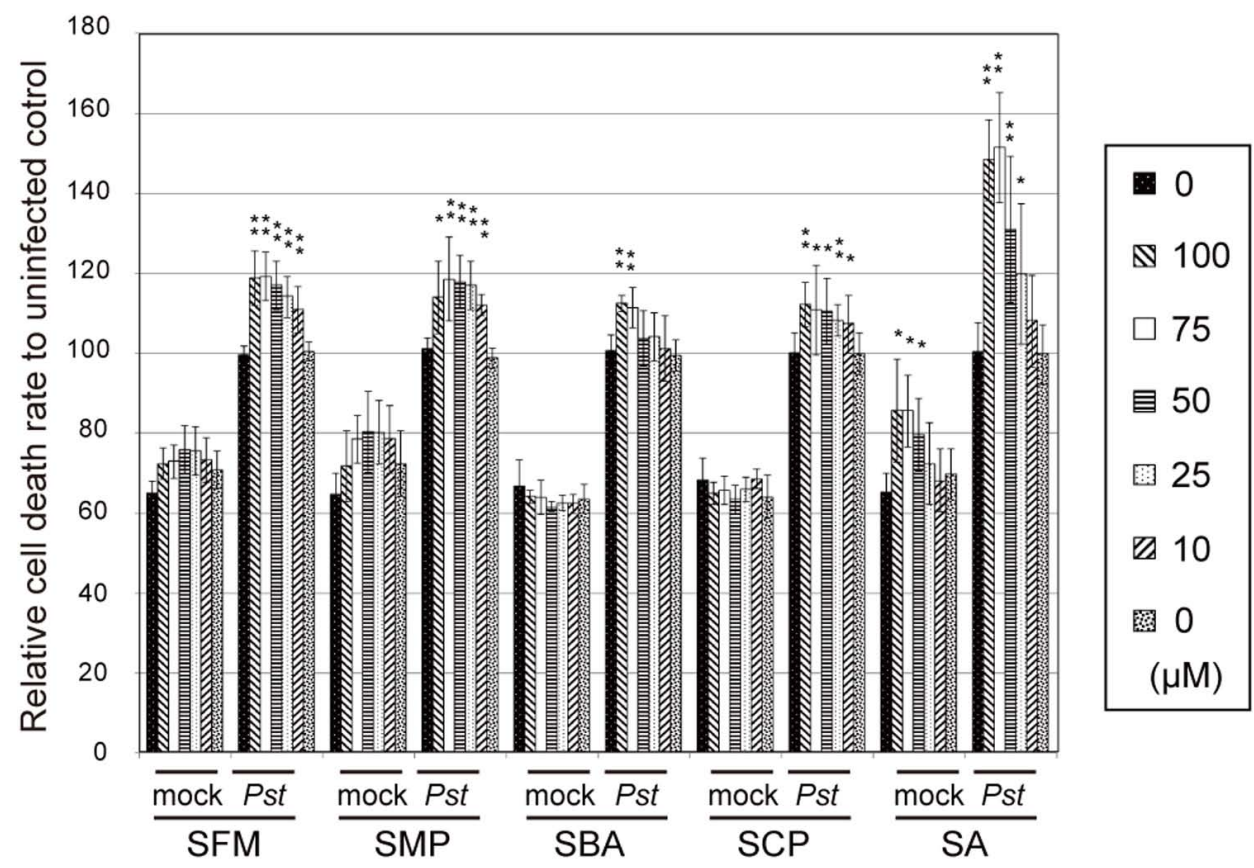

FIGURE 2 | The effects of the isolated sulfonamides on cell death in Arabidopsis suspension cultures upon challenge with pathogenic bacteria. The compounds were incubated with Arabidopsis suspension-cultured cells with or without the avirulent bacterial pathogen Pst-avrRpm1, and the degree of cell death was measured using Evans blue dye. Each cell death rate is shown as a value relative to the mean for the mock pathogen-treated group. SA was used as a positive control. The error bars represent mean \pm SE values of four independent replicates. ${ }^{*} P<0.01$; two-tailed Student's $t$ test with post hoc Bonferroni's correction 


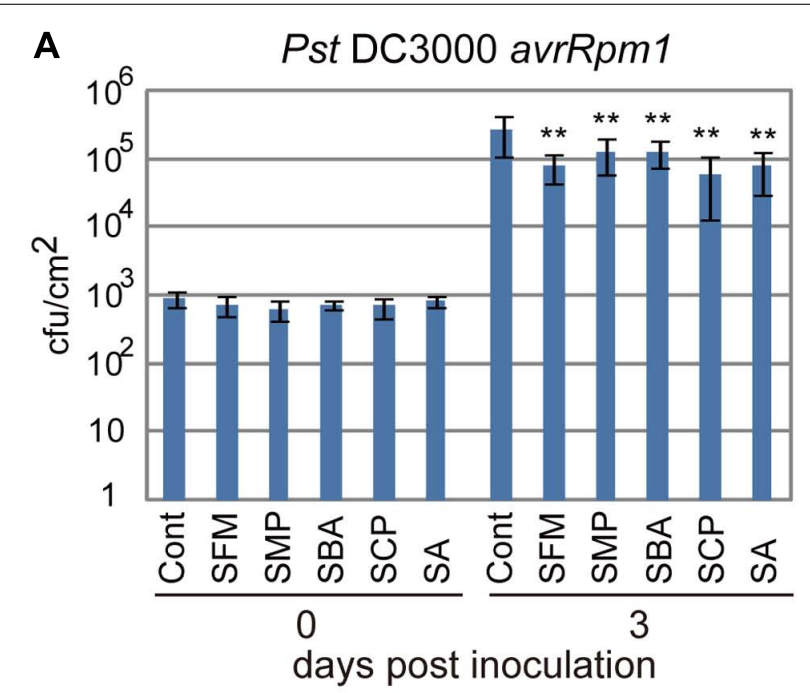

B

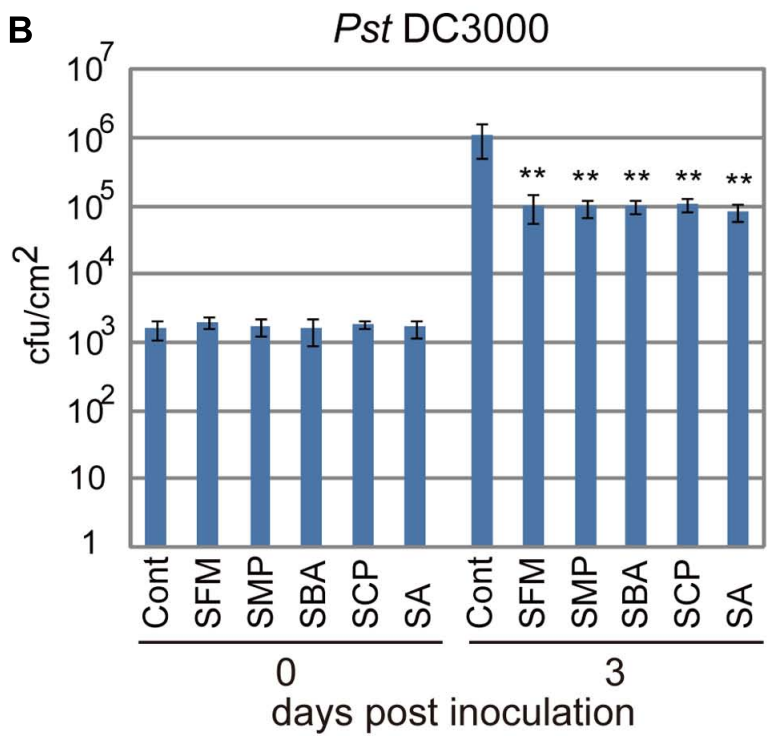

FIGURE 3 | Disease resistance of Arabidopsis plants treated with the sulfonamides. Arabidopsis plants grown on rockwool for 3 weeks under short-day conditions were drenched for 3 days with water supplemented with $100 \mu \mathrm{M}$ of each compound. As a positive control, $50 \mu \mathrm{M}$ of sodium salicylate (SA) was used. Then, the avirulent Pst-avrRpm1 (A) and the virulent Pst (B) were inoculated into leaves by infiltration with needle-less syringes $\left(\mathrm{OD}_{600}=0.002\right.$ in $\left.10 \mathrm{mM} \mathrm{MgCl}_{2}\right)$ and bacterial counts inside leaves were counted at 0 and 3 days after inoculation. The error bars represent mean \pm SE values $(n=7)$. ${ }^{*} P<0.01$; two-tailed Student's $t$ test. These data are representative of two independent replicates with similar results.

virulent and avirulent bacteria of Pst was inoculated into leaves with a needle-less syringe and the numbers of bacteria inside leaves were counted at the 3 days after inoculation. Compared with the control treatment, all the sulfonamide compounds significantly decreased the growth of the avirulent bacteria (Figure 3A). These data indicate that the sulfonamides function in planta and increase the disease resistance of Arabidopsis seedlings. In addition to disease resistance against the avirulent bacterial strain used in

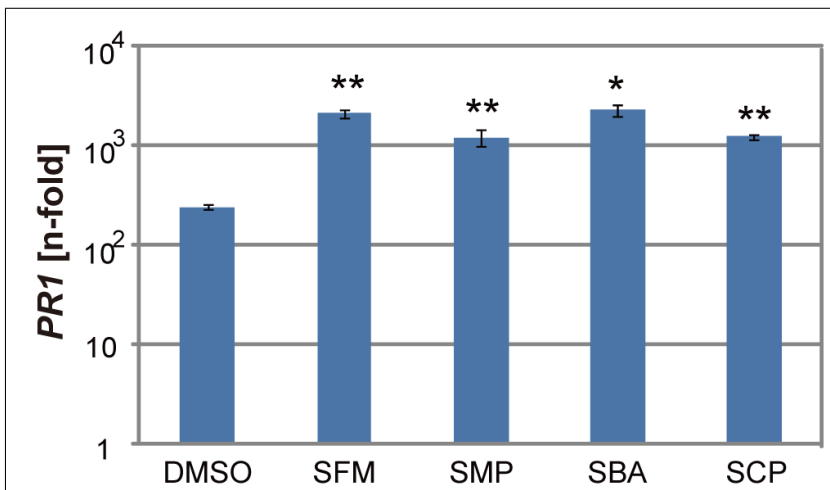

FIGURE 4 | Expression of the PR1 gene in the sulfonamide-treated Arabidopsis plants during pathogen infection. Hydroponically grown Arabidopsis seedlings were drenched with water containing $100 \mu \mathrm{M}$ of each chemical for 3 days before inoculation of Pst-avrRpm 1 with spraying. The mRNA levels of $P R 1$ were determined by qRT-PCR with cDNA prepared from samples at $24 \mathrm{~h}$ after inoculation. The expression values were normalized using Actin2 as an internal standard. The data was represented as relative values to the uninoculated samples with DMSO treatment. The error bars represent mean \pm SE values of three independent replicates. ${ }^{*} P<0.01$; two-tailed Student's $t$ test.

the screening, they also conferred disease resistance against the virulent Pst strain (Figure 3B). The degree of resistance conferred by these molecules was similar to that conferred by $50 \mu \mathrm{M}$ of SA. We also examined the expression level of $P R 1$, a marker of SA-dependent defense responses, in the chemical-treated Arabidopsis plants during infection by Pst-avrRpm1. Consistent with the increases in disease resistance, enhanced $P R 1$ gene expression was observed in plants treated with the sulfonamides (Figure 4).

\section{ACTIVITY OF THE SULFONAMIDES FOR INDUCTION OF DEFENSE GENES}

We examined if these isolated sulfonamide compounds induced defense genes like SA. Arabidopsis seedlings were treated with $100 \mu \mathrm{M}$ of these compounds for 24 or $48 \mathrm{~h}$, and the transcription of two defense genes, $P R$ and SA-inducible gene At3g57260, was analyzed by real-time qRT-PCR (Knoth et al., 2009). As shown in Figure 5, the sulfonamides did not induce the expression of the defense genes, in contrast to SA, which effectively upregulated their mRNA transcription at various time points. These results indicate that the sulfonamide compounds do not behave like analogs of SA. However, it is still possible that the sulfonamides induce defense genes at other timepoints within $24 \mathrm{~h}$.

\section{EFFECT OF THE SULFONAMIDES ON SA METABOLISM}

In our previous study, we found that perturbation of SA glucosylation, a major metabolic pathway during defense responses, is one of the modes of action of plant immune-priming agents (Dempsey etal., 2011; Noutoshi et al., 2012a). We isolated the immune-priming compounds imprimatin A and B from a chemical library of 10,000 small molecules by using our established screening procedure and found that they target known SAGTs and also novel SAGTs (Noutoshi et al., 2012a,b). Therefore, we examined whether the isolated sulfonamides inhibited the enzymatic activity of SAGTs. Each compound was added to the in vitro reaction mixture of one of the Arabidopsis SAGTs, UGT74F1, and 


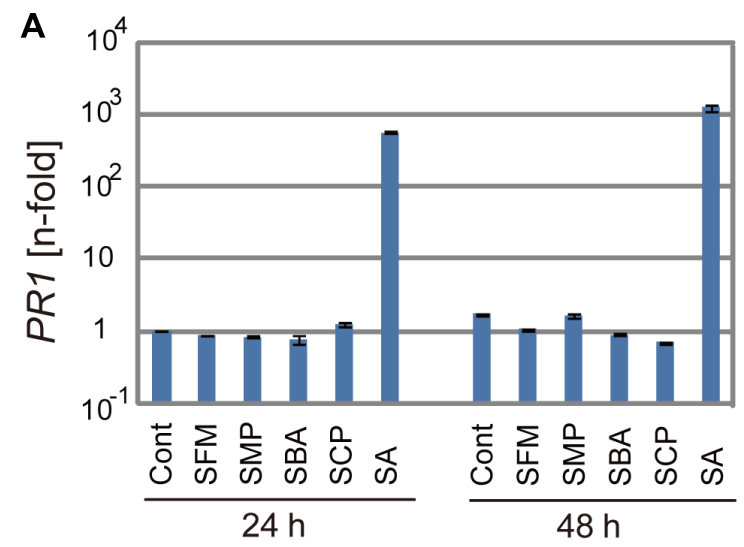

B

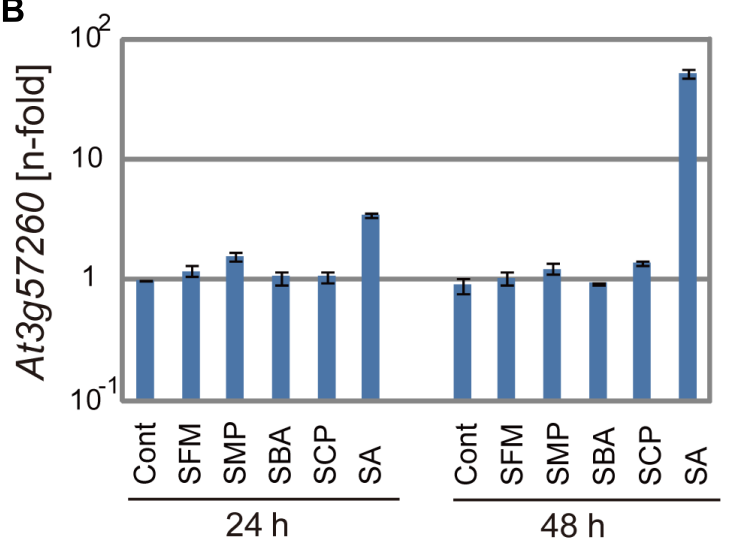

FIGURE 5 |The expression of defense genes after application of the sulfonamides. The mRNA levels of $P R 1$ (A) and At3g57260 (B) were determined by qRT-PCR with cDNA prepared from 10-day-old seedlings soaked for 24 or $48 \mathrm{~h}$ in liquid media containing $100 \mu \mathrm{M}$ of each chemical. The expression values of the individual genes were normalized using Actin2 as an internal standard. The data represent relative values with respect to the control. The bars represent the mean \pm SE values of three independent replicates.

their effects were evaluated. As compared with the imprimatin A2 positive control, which clearly inhibited SAGT activity, the sulfonamides did not prevent SAGT enzymatic activity at $100 \mu \mathrm{M}$, although SBA and SCP showed subtle inhibitory effects (Figure 6).

\section{EFFECTS OF THE KNOWN PROPERTY OF THE SULFONAMIDES ON IMMUNE-PRIMING}

Sulfonamides are known to function as antibiotics that inhibit folate biosynthesis by mimicking $p$-amino benzoate (PABA), a precursor of folate; however, their effective concentrations for bacterial growth suppression are varied (Brown, 1962; Yun et al., 2012). We tested if Pst growth is prevented in the presence of these isolated sulfonamides at effective concentration ranges for the potentiation of pathogen-induced cell death of Arabidopsis cell suspensions. The sulfonamides did not interrupt bacterial growth at least until a concentration of $200 \mu \mathrm{M}$, although we did not measure the chemical concentration in the leaves of the sulfonamide-treated Arabidopsis plants (Figure 7).

To determine the relationship between folate biosynthesis inhibition and the plant immune-priming effect of the sulfonamides,

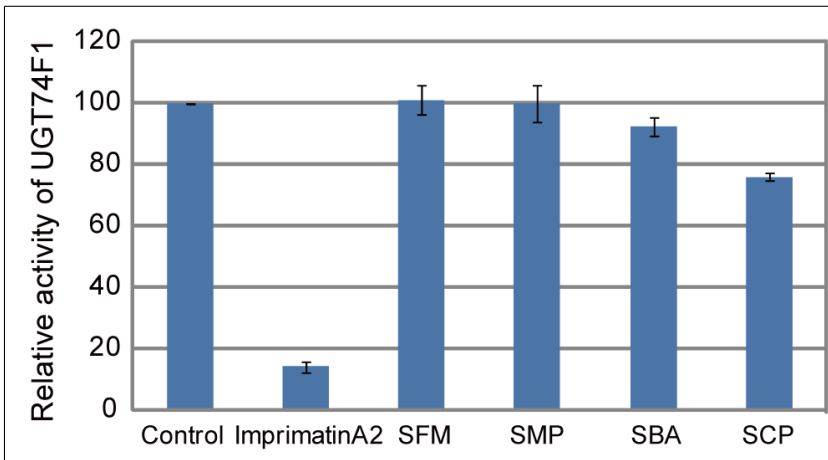

FIGURE 6 | Effect of the sulfonamides on the enzymatic activities of the SAGT. The levels of SA- $\beta$-D-glucoside (SAG) in the in vitro enzymatic reaction using affinity-purified histidine-tagged recombinant Arabidopsis UGT74F1 protein expressed in E. coli were measured by HPLC. The sulfonamides and imprimatin A2 were provided at a concentration of $100 \mu \mathrm{M}$. The data are shown as values relative to the DMSO control. The bars represent the mean \pm SE values of three independent replicates.

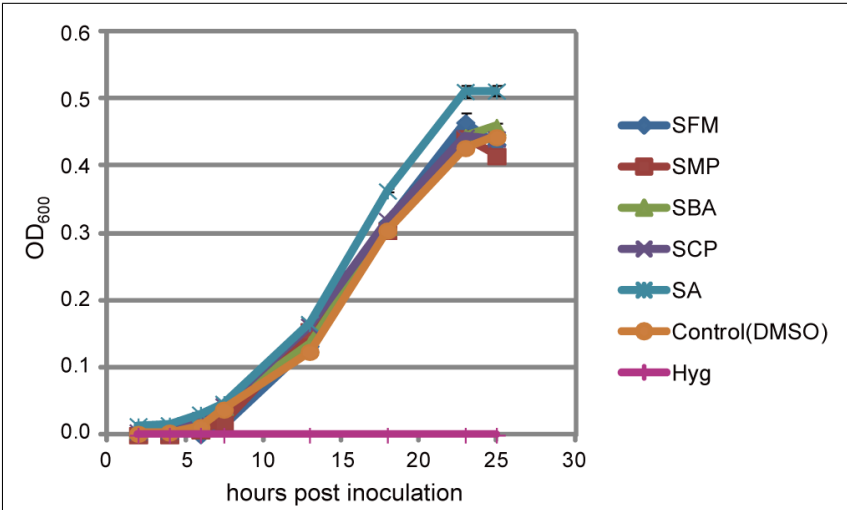

FIGURE 7 | Effect of the sulfonamides on bacterial growth. Pst was cultured in liquid minimal medium supplemented with $200 \mu \mathrm{M}$ of the indicated chemicals or $100 \mu \mathrm{g} / \mathrm{mL}$ hygromycin, and bacterial growth was monitored as the optical density of bacteria at $600 \mathrm{~nm}$ at the indicated times after inoculation. The bars represent the mean \pm SE values of three independent replicates.

we examined the effect of the isolated sulfonamides on plant growth. After sterilization and stratification, Arabidopsis seeds were incubated with MS liquid media containing sulfonamides at varied concentrations, as shown in Figure 8. Growth of Arabidopsis seedlings was severely suppressed by the sulfonamides (Figure 8). SBA and SCP prevented growth at $1 \mu \mathrm{M}$, whereas SFM and SMP inhibited growth at $10 \mu \mathrm{M}$. The growth-suppression effects of these compounds were restored by the addition of folate in a concentration-dependent manner (Figure 8). These results indicate that the isolated sulfonamides inhibit the growth of Arabidopsis seedlings through the perturbation of folate biosynthesis. However, the sulfonamides did not exhibit potentiation effects on pathogen-induced cell death at concentrations lower than $10 \mu \mathrm{M}$. This means that the inhibitory effect of the sulfonamides on folate biosynthesis would be independent of its chemical property for immune-priming. To confirm this hypothesis, we examined if application of folate can suppress the effect of the sulfonamides on 


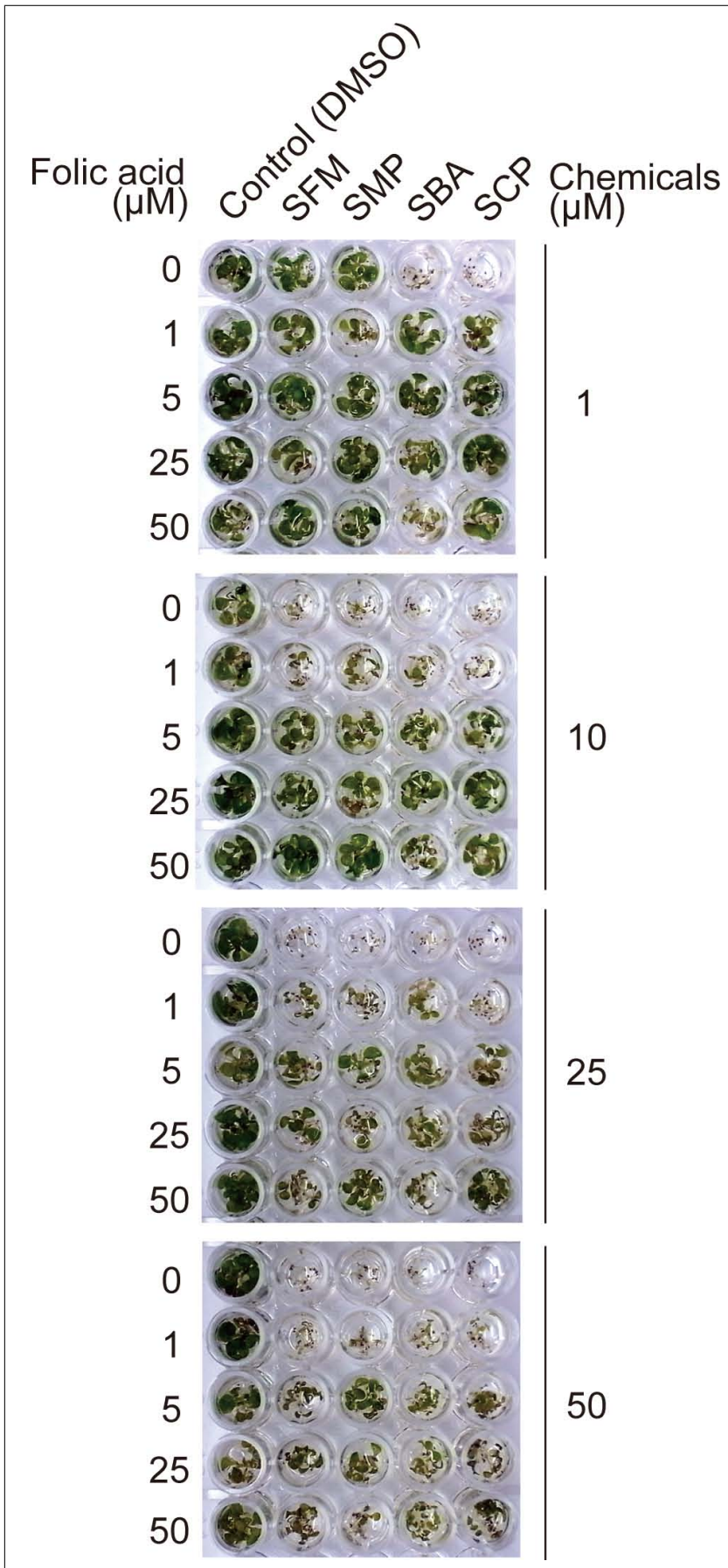

FIGURE 8 | The effect of the sulfonamides on germination of Arabidopsis thaliana. Arabidopsis seeds were dispensed into each well of a 96-well plate, and liquid media containing each sulfonamide and folic acid at the indicated concentrations were applied, followed by incubation under long-day conditions at $22^{\circ} \mathrm{C}$. Photographs were taken after 2 weeks. These data are representative of two independent replicates with similar results.

pathogen-induced cell death. As shown in Figure 9, the enhancement of pathogen-induced cell death by the four sulfonamides was not suppressed by the addition of at least 100 or $50 \mu \mathrm{M}$ of folate. These same concentrations of folate restore the seedling growth-suppressive effects of the sulfonamides. Therefore, these data suggest that different mechanisms of action are responsible for sulfonamide effects on seedling growth and pathogen-induced cell death.

\section{DISCUSSION}

In this study, we screened two different chemical libraries by using the established high-throughput chemical screening method for plant immune-priming compounds (Noutoshi et al., 2012a). Both chemical libraries are composed of bioactive substances and natural products, and the sulfonamide compounds were independently identified from each library (Figure 1). Although these compounds were obtained from a screening by using suspension cells, they conferred disease resistance to Arabidopsis whole plants against both virulent and avirulent strains of pathogenic bacteria (Figure 3). These results demonstrate that our screening procedure can be used for the isolation of lead plant activators as we expected.

These sulfonamides did not affect bacterial growth at the effective concentration range for the priming of immunity (Figure 7). However, they prevented Arabidopsis germination through the inhibition of folate biosynthesis (Figure 8). Our result is consistent with those of previous reports in that sulfanilamide, sulfadiazine (Sdiz), and sulfacetamide inhibit the enzymatic activity of dihydropteroate synthase (DHPS) in vitro with estimated $\mathrm{IC}_{50}$ values of 18.6, 9.6, and 4.2 $\mu \mathrm{M}$, respectively (Prabhu et al., 1997) and Sdiz prevents Arabidopsis germination at $1 \mathrm{mg} / \mathrm{L}(4 \mu \mathrm{M}$; Hadi et al., 2002). However, at least overnight incubation with the sulfonamides at $100 \mu \mathrm{M}$ did not affect the viability of the suspension cells (Figure 2) and thus they were isolated by our screening. This is consistent with the report that lethal doses of other sulfonamide compounds, sulfamethoxazole (Smex), Sdiz, and sulfapyridine (Spyr), for Arabidopsis seedlings are $2 \mathrm{mM}$ or more (Schreiber et al., 2008). These reports indicate that Arabidopsis is sensitive to sulfonamides only at early developmental stages, which could be due to the presence of less folic acid for de novo DNA synthesis. To avoid phytotoxic activity, the sulfonamides would need to be applied conditionally for immune activation.

As described above, sulfonamides are known to mimic PABA and inhibit folate biosynthesis (Brown, 1962). Because PABA is biosynthesized from chorismate in the shikimate pathway, sulfonamide application might increase the cellular chorismate pool. A large amount of SA is synthesized de novo during disease resistance responses by the function of isochorismate synthase (Wildermuth et al., 2001); therefore, the sulfonamides might facilitate SA accumulation in response to pathogen challenge. Based on the analogy that the sulfonamides can mimic a benzoate derivative PABA, we speculated that the sulfonamides might be able to mimic SA at a high concentration range. However, the sulfonamides did not behave like SA at least at $100 \mu \mathrm{M}$ (Figure 5). We have previously identified imprimatin $\mathrm{A}$ and $\mathrm{B}$ as plant immune-priming compounds from the same screening system and found that they enhanced immune responses by inhibiting the SAGTs involved in SA metabolism (Noutoshi et al., 2012a,b). These imprimatin compounds were incorporated into SAGTs instead of SA and inhibited the glucosylation of SA (Noutoshi et al., 2012a). As demonstrated in Figure 6, the sulfonamides did not function as SAGT 

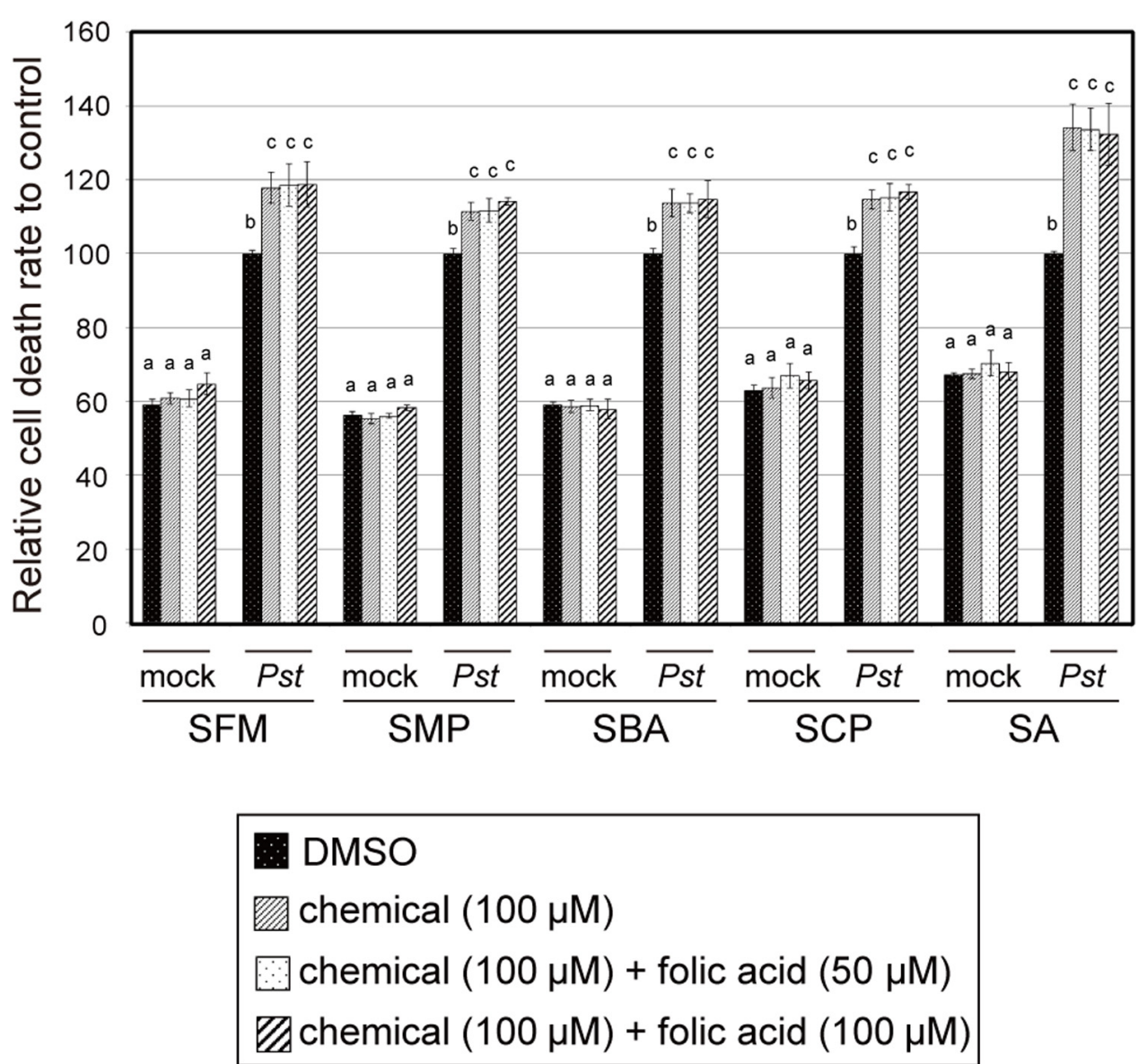

FIGURE 9 | The effect of folate on the sulfonamide-dependent cell death enhancement of Arabidopsis suspension cultures induced by

Pst-avrRpm 1. The sulfonamide compounds and folate were incubated with Arabidopsis suspension-cultured cells at the indicated concentrations, with or without the avirulent bacterial pathogen Pst-avrRpm1, and the degree of cell death was measured in terms of the concentration of Evans blue dye. Each cell death rate is shown as a value relative to the mean of the mock pathogen-treated group. Sodium salicylate (SA) was used as a positive control. The error bars represent the mean \pm SE values of five independent replicates. The letters indicate statistically significant differences between treatments (one-way ANOVA, Tukey's post hoc test, $P<0.05$ ). The experiment was repeated three times with similar results. inhibitors; therefore, they behave differently from imprimatin $\mathrm{A}$ and $\mathrm{B}$.

Recently, sulfamethazine (SMZ) was isolated as a chemical suppressor of epigenetic silencing (Zhang et al., 2012). SMZ treatment suppresses the silencing of transgenes, endogenous transposons, and other repetitive elements. These chemical effects are due to decreased cellular pools of folate and $S$-adenosylmethionine and leads to a reduction in DNA methylation levels and histone H3 Lys-9 dimethylation levels (Zhang et al., 2012). The involvement of epigenetics in priming events was also suggested by another report (Jaskiewicz et al., 2011). The increased levels of methylation and acetylation of lysine residues of the histones $\mathrm{H} 3$ and $\mathrm{H} 4$ were observed on the promoter regions of the WRKY6, WRKY29, and WRKY53 genes in primed plants after treatment with BTH or a pathogen (Jaskiewicz et al., 2011). Although the methylation status in these reports is not generally consistent, these findings led us to speculate that alteration of histone modifications induced by folate biosynthesis inhibition could be a cause of the immune-priming of the sulfonamide compounds. However, since application of folate did not restore the sulfonamide-induced cell death enhancement (Figure 9), we conclude that the sulfonamides upregulate the pathogen-induced cell death through an unknown mechanism.

Sulfonamide compounds were also identified as a protectant for A. thaliana whole seedlings exposed to bleaching induced by the cocultivation of virulent Pst (Schreiber et al., 2008). Our results showed that $100 \mu \mathrm{M}$ of Smex significantly suppressed the growth of bacterial pathogens inside Arabidopsis seedlings. Smex has also been found to suppress symptoms of infection by a cereal pathogen Fusarium graminearum in both Arabidopsis and wheat (Schreiber et al., 2011). Interestingly, sulfanilamide has no plantprotective activity although it has a structure closely similar to that of the isolated sulfonamides (Schreiber et al., 2008, 2011). Recently, we have also identified three diuretic compounds, bumetanide, bendroflumethiazide, and clopamide, as plant immune-priming compounds from the screening (Noutoshi et al., 2012c). Interestingly, these three diuretics share the same sulfonamide functional group (Noutoshi et al., 2012c). Considering 
these findings, only $\mathrm{RSO}_{2} \mathrm{NH}_{2}$ with particular R-groups might have immune-activating properties in plants. Large-scale structure-activity relationship analysis using various sulfonamide derivatives will help identify minimal structural requirements for immune activity as well as provide effective leads for practical application.

\section{REFERENCES}

Brown, G. M. (1962). The biosynthesis of folic acid. II. Inhibition by sulfonamides. J. Biol. Chem. 237, 536-540.

Conrath, U. (2011). Molecular aspects of defence priming. Trends Plant Sci. 16, 524-531.

Dangl, J. L., and Jones, J. D. (2001). Plant pathogens and integrated defence responses to infection. Nature 411, 826-833.

Dempsey, D. A., Vlot, A. C., Wildermuth, M. C., and Klessig, D. F. (2011). Salicylic acid biosynthesis and metabolism. Arabidopsis Book 9, e0156. doi: 10.1199/tab.0156

Gorlach, J., Volrath, S., Knauf-Beiter, G., Hengy, G., Beckhove, U., Kogel, K. H., et al. (1996). Benzothiadiazole, a novel class of inducers of systemic acquired resistance, activates gene expression and disease resistance in wheat. Plant Cell 8, 629-643.

Hadi, M. Z., Kemper, E., Wendeler, E., and Reiss, B. (2002). Simple and versatile selection of Arabidopsis transformants. Plant Cell Rep. 21, 130-135.

Himmler, T. (2004). Method for producing 3,4-dichloro-N-(2-cyanophenyl)-5-isothiazole carboxamide. PCT/EP2003/006360. Available at: http://patentscope.wipo.int/search/ en/WO2004002968

Iwai, T., Seo, S., Mitsuhara, I., and Ohashi, Y. (2007). Probenazoleinduced accumulation of salicylic acid confers resistance to Magnaporthe grisea in adult rice plants. Plant Cell Physiol. 48, 915-924.

Jaskiewicz, M., Conrath, U., and Peterhansel, C. (2011). Chromatin modification acts as a memory for systemic acquired resistance in the plant stress response. EMBO Rep. 12, 50-55.

Kano, A., Gomi, K., Yamasaki-Kokudo, Y., Satoh, M., Fukumoto, T., Ohtani, K., etal. (2010). A rare sugar, Dallose, confers resistance to rice bacterial blight with upregulation of defense-related genes in Oryza sativa. Phytopathology 100, 85-90.

Kano, A., Hosotani, K., Gomi, K., Yamasaki-Kokudo, Y., Shirakawa, C., Fukumoto, T., et al. (2011). D-Psicose induces upregulation of defenserelated genes and resistance in rice against bacterial blight. J. Plant Physiol. 168, 1852-1857.
Knoth, C., Salus, M. S., Girke, T., and Eulgem, T. (2009). The synthetic elicitor 3,5-dichloroanthranilic acid induces NPR1-dependent and NPR1-independent mechanisms of disease resistance in Arabidopsis. Plant Physiol. 150, 333-347.

Lawton, K. A., Friedrich, L., Hunt, M., Weymann, K., Delaney, T., Kessmann, H., et al. (1996). Benzothiadiazole induces disease resistance in Arabidopsis by activation of the systemic acquired resistance signal transduction pathway. Plant J. 10, 71-82.

Maor, R., Jones, A., Nuhse, T. S., Studholme, D. J., Peck, S. C., and Shirasu, K. (2007). Multidimensional protein identification technology (MudPIT) analysis of ubiquitinated proteins in plants. Mol. Cell. Proteomics 6, 601-610.

Menges, M., and Murray, J. A. (2002). Synchronous Arabidopsis suspension cultures for analysis of cell-cycle gene activity. Plant J. 30, 203-212.

Mur, L. A., Kenton, P., Lloyd, A. J., Ougham, H., and Prats, E. (2008). The hypersensitive response; the centenary is upon us but how much do we know? J. Exp. Bot. 59, 501-520.

Nakashita, H., Yoshioka, K., Yasuda, M., Nitta, T., Arai, Y., Yoshida, S., et al. (2002). Probenazole induces systemic acquired resistance in tobacco through salicylic acid accumulation. Physiol. Mol. Plant Pathol. 61, 197-203.

Noutoshi, Y., Ito, T., Seki, M., Nakashita, H., Yoshida, S., Marco, Y., et al. (2005). A single amino acid insertion in the WRKY domain of the Arabidopsis TIR-NBS-LRR-WRKY-type disease resistance protein SLH1 (sensitive to low humidity 1) causes activation of defense responses and hypersensitive cell death. Plant J. 43, 873-888.

Noutoshi, Y., Ito, T., Seki, M., Nakashita, H., Yoshida, S., Marco, Y., et al. (2006). Loss of necrotic spotted lesions 1 associates with cell death and defense responses in Arabidopsis thaliana. Plant Mol. Biol. 62, 29-42.

Noutoshi, Y., Okazaki, M., Kida, T., Nishina, Y., Morishita, Y., Ogawa, T., et al. (2012a). Novel plant immunepriming compounds identified via

\section{ACKNOWLEDGMENTS}

We wish to thank Ms Akiko Ueno for the maintenance of cell cultures. This work was supported in part by KAKENHI (no. 22780036 to Yoshiteru Noutoshi and 24228008 to Ken Shirasu) and the Special Coordination Fund for Promoting Sciences and Technology of MEXT to Yoshiteru Noutoshi.

high-throughput chemical screening target salicylic acid glucosyltransferases in Arabidopsis. Plant Cell. doi: 10.1105/tpc.112.098343 [Epub ahead of print].

Noutoshi, Y., Okazaki, M., and Shirasu, K. (2012b). Isolation and characterization of the plant immune-priming compounds Imprimatin B3 and $\mathrm{B} 4$, potentiators of disease resistance in Arabidopsis thaliana. Plant Signal. Behav. doi: 10.4161/psb.22368 [Epub ahead of print].

Noutoshi, Y., Ikeda, M., and Shirasu, K. (2012c). Diuretics prime plant immunity in Arabidopsis thaliana. PLOS ONE doi: 10.1371/journal. pone. 0048443 [Epub ahead of print]. Osada, H. (2010). Introduction of new tools for chemical biology research on microbial metabolites. Biosci. Biotechnol. Biochem. 74, 1135-1140.

Prabhu, V., Lui, H., and King, J. (1997). Arabidopsis dihydropteroate synthase: general properties and inhibition by reaction product and sulfonamides. Phytochemistry 45, 23-27.

Schreiber, K., Ckurshumova, W., Peek, J., and Desveaux, D. (2008). A highthroughput chemical screen for resistance to Pseudomonas syringae in Arabidopsis. Plant J. 54, 522-531.

Schreiber, K., and Desveaux, D. (2008). Message in a bottle: chemical biology of induced disease resistance in plants. Plant Pathol. J. 24, 245-268.

Schreiber, K. J., Nasmith, C. G., Allard, G., Singh, J., Subramaniam, R., and Desveaux, D. (2011). Found in translation: high-throughput chemical screening in Arabidopsis thaliana identifies small molecules that reduce Fusarium head blight disease in wheat. Mol. Plant Microbe Interact. 24, 640-648.

Serrano, M., Robatzek, S., Torres, M., Kombrink, E., Somssich, I. E., Robinson, M., et al. (2007). Chemical interference of pathogen-associated molecular pattern-triggered immune responses in Arabidopsis reveals a potential role for fatty-acid synthase type II complex-derived lipid signals. J. Biol. Chem. 282, 6803-6811.

Shirano, Y., Kachroo, P., Shah, J., and Klessig, D. F. (2002). A gain-offunction mutation in an Arabidopsis Toll interleukin1 receptor-nucleotide binding site-leucine-rich repeat type $R$ gene triggers defense responses and results in enhanced disease resistance. Plant Cell 14, 3149-3162.

Shirasu, K., Nakajima, H., Rajasekhar, V. K., Dixon, R. A., and Lamb, C. (1997). Salicylic acid potentiates an agonist-dependent gain control that amplifies pathogen signals in the activation of defense mechanisms. Plant Cell 9, 261-270.

Tsubata, K., Kuroda, K., Yamamoto, Y., and Yasokawa, N. (2006). Development of a novel plant activator for rice diseases, tiadinil. J. Pestic. Sci. 31, 161-162.

Umemura, K., Satou, J., Iwata, M., Uozumi, N., Koga, J., Kawano, T., et al. (2009). Contribution of salicylic acid glucosyltransferase, OsSGT1, to chemically induced disease resistance in rice plants. Plant J. 57, 463-472.

Vlot, A. C., Dempsey, D. A., and Klessig, D. F. (2009). Salicylic acid, a multifaceted hormone to combat disease. Annu. Rev. Phytopathol. 47, 177-206.

Ward, E. R., Uknes, S. J., Williams, S. C., Dincher, S. S., Wiederhold, D. L., Alexander, D. C., et al. (1991). Coordinate gene activity in response to agents that induce systemic acquired resistance. Plant Cell 3, 1085-1094.

Watanabe, T., Igarashi, H., Matsumoto, K., Seki, S., Mase, S., and Sekizawa, Y. (1977). The characteristics of probenazole (Oryzemate ${ }^{\circledR}$ ) for the control of rice blast. J. Pestic. Sci. 2 , 291-296.

Weigel, D., and Glazebrook, J. (2002). Arabidopsis: A Laboratory Manual. Cold Spring Harbor, NY: Cold Spring Harbor Laboratory Press.

Wildermuth, M. C., Dewdney, J., Wu, G., and Ausubel, F. M. (2001). Isochorismate synthase is required to synthesize salicylic acid for plant defence. Nature 414, 562-565.

Yang, D. L., Yao, J., Mei, C. S., Tong, X. H., Zeng, L. J., Li, Q., et al. (2012). Plant hormone jasmonate prioritizes defense over growth by interfering with gibberellin signaling cascade. Proc. Natl. Acad. Sci. U.S.A. 109, E1192-E1200.

Yasuda, M., Kusajima, M., Nakajima, M., Akutsu, K., Kudo, T., Yoshida, S., et al. (2006). Thiadiazole carboxylic acid moiety of tiadinil, SV-03, 
induces systemic acquired resistance in tobacco without salicylic acid accumulation. J. Pestic. Sci. 31, 329-334.

Yoshioka, K., Nakashita, H., Klessig, D. F., and Yamaguchi, I. (2001). Probenazole induces systemic acquired resistance in Arabidopsis with a novel type of action. Plant J. 25, 149-157.

Yun, M. K., Wu, Y., Li, Z., Zhao, Y., Waddell, M. B., Ferreira, A. M., et al. (2012). Catalysis and sulfa drug resistance in dihydropteroate synthase. Science 335, 1110-1114.

Zhang, H., Deng, X., Miki, D., Cutler, S., La, H., Hou, Y. J., et al. (2012).
Sulfamethazine suppresses epigenetic silencing in Arabidopsis by impairing folate synthesis. Plant Cell 24, 1230-1241.

Zhang, Y., Goritschnig, S., Dong, X. and Li, X. (2003). A gain-of-function mutation in a plant disease resistance gene leads to constitutive activation of downstream signal transduction pathways in suppressor of npr1-1, constitutive 1. Plant Cell 15, 26362646.

Conflict of Interest Statement: The authors declare that the research was conducted in the absence of any commercial or financial relationships that could be construed as a potential conflict of interest.

Received: 06 August 2012; accepted: 14 October 2012; published online: 31 October 2012.

Citation: Noutoshi Y, Ikeda M, Saito T, Osada H and Shirasu K (2012) Sulfonamides identified as plant immunepriming compounds in high-throughput chemical screening increase disease resistance in Arabidopsis thaliana. Front.
Plant Sci. 3:245. doi: 10.3389/fpls.2012. 00245

This article was submitted to Frontiers in Plant-Microbe Interaction, a specialty of Frontiers in Plant Science.

Copyright (c) 2012 Noutoshi, Ikeda, Saito, Osada and Shirasu. This is an openaccess article distributed under the terms of the Creative Commons Attribution License, which permits use, distribution and reproduction in other forums, provided the original authors and source are credited and subject to any copyright notices concerning any third-party graphics etc. 